\title{
ASSESSMENT OF SELF-EXTRACTED CELLULOSE FROM ORYZA SATIVA FOR DESIGN OF CONTROLLED DRUG DELIVERY SYSTEM OF DALFAMPRIDINE
}

\author{
JEEVANA JYOTHI B*, MOUNIKA M, \\ Department of Institute of Pharmaceutical Technology, Sri PadmavatiMahilaVisvavidyalayam (Women's University), Tirupati, \\ Andhra Pradesh, India. Email: jeevanajyothib@yahoo.com
}

Received: 17 October 2018, Revised and Accepted: 5 December 2018

ABSTRACT

Objectives: The main objective of the present work includes extraction of cellulose from Oryza sativa (OS), characterization of cellulose, development of controlled release tablet dalfampridine using cellulose of $\mathrm{OS}$, and in vitro evaluation.

Methods: Dry powdered OS husk sample was extracted with a mixture of hexane and methanol (2:1, v/v) using soxhlation method and was characterized by solubility, melting point determination, differential scanning calorimetry (DSC), and Fourier-transform infrared (FTIR) analysis. Compatibility between dalfampridine and the mixture of cellulose with dalfampridine was confirmed by FTIR and DSC analysis. Then, controlled drug delivery system of dalfampridine were prepared as directly compressed tablets using various compositions containing OS cellulose, hydroxypropyl methylcellulose (HPMC), dicalcium phosphate, and magnesium stearate ( 8 nos. F1 to f8) and were evaluated.

Results: Cellulose was extracted from OS extract to possess its ideal characteristics. Dalfampridine and its mixture with cellulose were compatible according to FTIR and DSC analysis. Directly compressed tablets made with $10 \mathrm{mg}$ of dalfampridine and OS cellulose, HPMC, dicalcium phosphate, and magnesium stearate evidenced prolonged and controlled drug delivery of dalfampridine for $12 \mathrm{~h}$. Formulation made with OS cellulose 250 mg, HPMC $20 \mathrm{mg}$, dicalcium phosphate $40 \mathrm{mg}$, and magnesium stearate $5 \mathrm{mg}$ was ideal without burst release.

Conclusion: Cellulose extracted from OS is used successfully for the production of directly compressed tablets of dalfampridine to elicit optimum characteristics including controlled drug delivery for $12 \mathrm{~h}$.

Keywords: Cellulose from Oryza sativa, Soxhlation method, Fourier-transform infrared, Compatibility, Dalfampridine, Controlled delivery.

(C) 2019 The Authors. Published by Innovare Academic Sciences Pvt Ltd. This is an open access article under the CC BY license (http://creativecommons. org/licenses/by/4. 0/) DOI: http://dx.doi.org/10.22159/ajpcr.2019.v12i2.29785

\section{INTRODUCTION}

Synthetic polymers and celluloses are generally utilized for the design of controlled or novel drug delivery systems. There are chances of toxic effects produced from synthetic polymers or celluloses. At this juncture, natural polymers reported with less toxicity and high biodegradability can be taken as a choice for the design of formulations of drugs. Cellulose is one of the polymers used in biomedical applications. It was reported that all-cellulose composites possess an intriguing combination of high strength and biodegradability [1]

Therefore, in the present research work, we have exploited cellulose from Oryza sativa (OS) for the design of drug for the treatment of multiple sclerosis (MS) as there are no reports for utilization of this cellulose in the development of drug delivery systems. Formulations.

$\mathrm{OS}(\mathrm{RH})$ is one of the major agricultural residues generated as a byproduct during the rice milling process. According to Jackson, OS consists of $33 \%$ cellulose, $26 \%$ hemicellulose, and $7 \%$ lignin. Cellulose is a polysaccharide made of d-glucose connected through -1,4-glycosidic bonds and is a promising raw material for producing important chemicals, including cellulosic ethanol, hydrocarbons, and starting materials to produce polymers [2].

At present, the model drug selected is dalfampridine which is recently approved by the FDA in January 2010 for symptomatic treatment of MS patients with a specific indication for improvement in walking. In the past, 4-aminopyridine has been used as an experimental agent which presumably enhances nerve conduction of demyelinated axons through its effects on potassium channels for the treatment of fatigue in MS.
Moreover, now, dalfampridine is used successfully. Hence, it is aimed to design in the form of controlled-release tablets.

The work involves four objectives such as extraction of cellulose from OS, characterization of cellulose, development of controlled release tablet dalfampridine, and in vitro evaluation.

\section{MATERIALS AND METHODS}

\section{Materials}

Dalfampridine was purchased from Simpson Pharmacy, Mumbai. $\mathrm{n}$-Hexane, methanol, hydrogen peroxide, liquid nitrogen, $\mathrm{KBr}$, hydroxypropyl methylcellulose (HPMC), dicalcium phosphate, and magnesium stearate were purchased from SD Fine Chemicals Ltd.

\section{Methods}

Isolation of cellulose from $O S$

Dry powdered OS husk sample was extracted with a mixture of hexane and methanol $(2: 1, \mathrm{v} / \mathrm{v})$ using soxhlation method for $10 \mathrm{~h}$ for removal of oil/wax, etc. Then, the delignification is done a follow-up with using two-step processes usually. At first, the extractive-free OS husk (10 g) was soaked in $300 \mathrm{ml}$ different alkalis $(5 \%, \mathrm{w} / \mathrm{v})$ with a ratio of liquor to the material $(30: 1)$ and heated to $80^{\circ} \mathrm{C}$ for $5 \mathrm{~h}$. Then, the collected slurry can cool. Then, it is treated with $10 \% \mathrm{H}_{2} \mathrm{SO}_{4}$ to neutralize the solution. Then, it adjusts to $3-4$ of $\mathrm{pH}$ value at $50^{\circ} \mathrm{C}[3,4]$.

After extraction, residual biomass was separated by filtration through Buchner funnel connected to a vacuum pump. The residual biomass was undertaken for bleaching treatment using $2 \% \mathrm{H}_{2} \mathrm{O}_{2}$ solution with adjusting $\mathrm{pH}$ value 9 and the ratio of liquor to the materials (30:1) and 
stirred for $5 \mathrm{~h}$ at room temperature [5] Then, the biomass was cleaned with distilled water specifically for many times to attain chemical free product including $\mathrm{H}_{2} \mathrm{O}_{2}$. The collected samples were filtered and, in an oven, sieved through 40 mesh screen and stored in the airtight container to prevent oxidation for the future use.

\section{Characterization of cellulose}

Extracted cellulose was characterized by solubility, melting point determination, differential scanning calorimetry (DSC), and Fouriertransform infrared (FTIR) analysis.

\section{Solubility of cellulose}

Pretreatment of cellulose: Ethanol acid pre-treatment

In a water bath, add several liters of cold distilled water to remove unnecessary chemicals and for cooling. Ethanol was pre-heated to $60^{\circ} \mathrm{C}$. Then, when thermal equilibration was reached, hydrochloric acid (37wt.\%) was added. $16 \mathrm{~g}$ of cellulose pulp was added to ensure homogeneous dispersion of the cellulose in the ethanol-acid medium, especially under continuous stirring that the performed reaction was stopped after $30 \mathrm{~min}$. Then, to remove any residuals of ethanol and $\mathrm{HCl}$ completely, the collected biomass was filtered and washed with distilled water [6]

Solubility:

As cellulose is insoluble in water, a freshly prepared solvent system $\left(\mathrm{NaOH} / \mathrm{H}_{2} \mathrm{O}\right)$ pre-cooled to $-1^{\circ} \mathrm{C}$ was tried test solubility [7]. The solution was kept in a freezer at $0^{\circ} \mathrm{C}$. Then, the cellulose was added to the solvent in a cooled container refrigerated through circulation of a water-polyethylene glycol solution. Each solution was stirred for $20 \mathrm{~min}$ at $500 \mathrm{rpm}$. The temperature was kept at $-1^{\circ} \mathrm{C}$ during the first couple of minutes and then increased to $+4^{\circ} \mathrm{C}$.

\section{Melting point}

Melting point of prepared cellulose was determined by open capillary tube method [6]. The capillary tube was closed at one end by fusion and was filled with the drug on the other end by repeated tapings. The capillary tube was placed on apparatus. The instrument was set to automatically increase the temperature of the heating bath at a rate of $1^{\circ} \mathrm{C}$ per minute. The temperature at which the drug started melting is recorded. This was performed thrice, and their average was taken as a result.

DSC

DSC analysis was carried out for the cellulose of OS using DSC (Mettler, Toledo, Switzerland) and scanned for a range of $10^{\circ} \mathrm{C} / \mathrm{min}$ under static air atmosphere.

\section{FTIR}

FTIR spectrum of extracted cellulose was obtained using IR spectrophotometer (Bruker, JAPAN) by $\mathrm{KBr}$ pressed pellet technique. The scanning range was $4000-400 \mathrm{~cm}^{-1}$ and the resolution was $1 \mathrm{~cm}^{-1}$.

Drug-excipient interaction study of dalfampridine with cellulose of OS

As the present work was to develop controlled drug delivery system of dalfampridine using the self-extracted cellulose of OS, drug-

Table 1: Composition of dalfampridine controlled-release tablets

\begin{tabular}{lllllllll}
\hline Ingredients (mg) & F1 & F2 & F3 & F4 & F5 & F6 & F7 & F8 \\
\hline Dalfampridine & 10 & 10 & 10 & 10 & 10 & 10 & 10 & 10 \\
RH cellulose & 150 & 125 & 200 & 200 & - & 250 & 300 & - \\
HPMC & 29 & 89 & 30 & - & 105 & 20 & -10 \\
Dicalcium phosphate & 131 & 106 & 80 & 110 & 205 & 40 & 120 \\
Magnesium stearate & 5 & 5 & 5 & 5 & 5 & 5 & 5 \\
Total & 325 & 325 & 325 & 325 & 325 & 325 & 325 & 325 \\
\hline
\end{tabular}

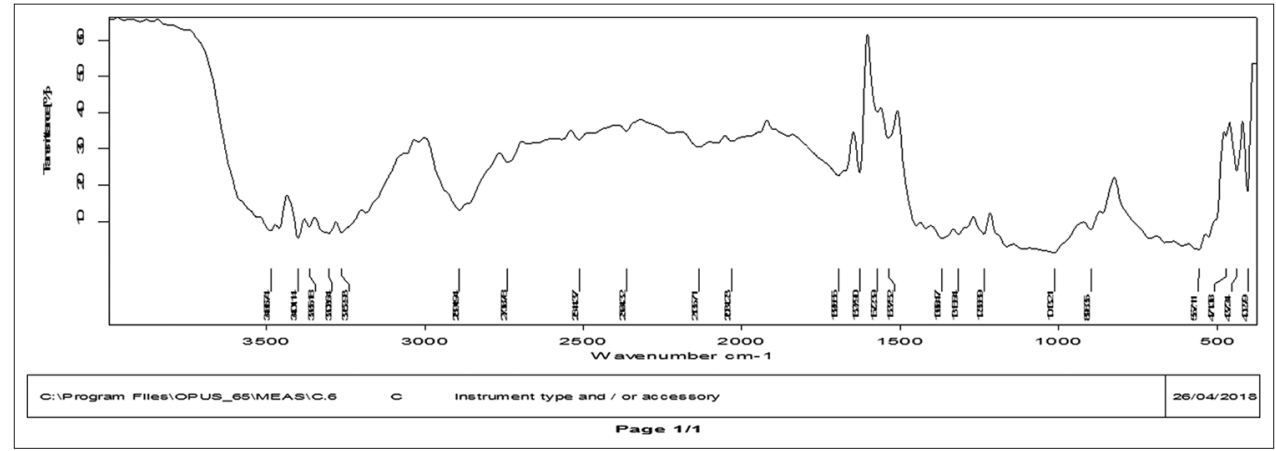

Fig. 1: The alkali (liquid ammonia)-treated Oryza sativa cellulose Fourier-transform infrared

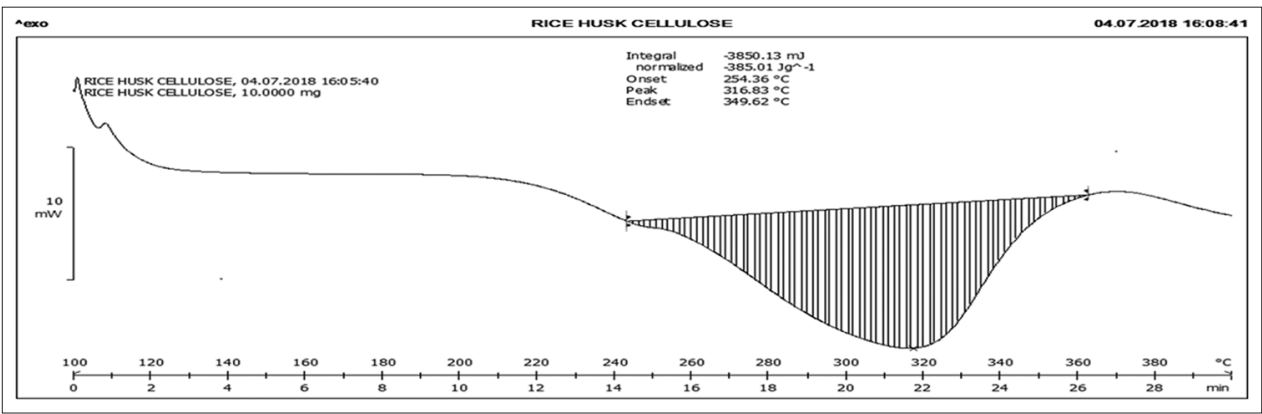

Fig. 2: Differential scanning calorimetry of Oryza sativa cellulose 
Table 2: Oryza sativa cellulose functional group identification

\begin{tabular}{lll}
\hline Functional groups & $\begin{array}{l}\text { Reference wave } \\
\text { number }\end{array}$ & $\begin{array}{l}\text { Observed wave } \\
\text { number }\end{array}$ \\
\hline OH Stretching & 3990 & 3386 \\
C=O Stitching & 1751 & 1896 \\
C-H Bending & 1369 & 1315.84 \\
C-O Stretching & 1220 & 1236.89 \\
C-O-C Pyranose ring & 1384 & 1388.47 \\
$\beta$-glycoside linkage & 910 & 858.35 \\
O-H Bending & 1384 & 1388.47 \\
\hline
\end{tabular}

Table 3: IR absorption peaks of pure dalfampridine and its mixture with Oryza sativa cellulose

\begin{tabular}{lll}
\hline Functional group & $\begin{array}{l}\text { Reference wave } \\
\text { number }\left(\mathbf{c m}^{-1}\right)\end{array}$ & $\begin{array}{l}\text { Wave } \\
\text { number } \mathbf{( \mathbf { c m } ^ { - 1 } )}\end{array}$ \\
\hline NH-Stretching & 3437.37 & 3304.56 \\
CH (aromatic) stretching & 3031.66 & 3061.13 \\
C=N & 1648.46 & 1648.76 \\
C=C & 1504.49 & 1505.20 \\
CH-Bending & 1433.83 & 1433.43 \\
\hline
\end{tabular}

excipient interaction studies were carried out to assess compatibility between them. Hence, DSC thermogram and FTIR spectrum were taken for the mixture of dalfampridine and cellulose of OS and were compared.

\section{Preparation of dalfampridine tablets}

Controlled release tablets containing $10 \mathrm{mg}$ of dalfampridine were prepared using self-extracted OS cellulose by direct compression [6]. Eight formulations, F1-F8, were tried and their composition is given in Table 1 . The ingredients necessary for the preparation of 100 were accurately weighed and mixed in a polyethylene bag. Then, the material was sieved through \#40 and determined for micromeritic properties. Lubricated blend was then compressed into tablets using oval-shaped B tooling punches using $13 \mathrm{KP}$ pressure to get $325 \mathrm{mg}$ in 10 station rotary compression machine (Rimek, Mumbai).

Evaluation of pre-compression characteristics

Pre-compression parameters such as angle of repose, bulk density, and tapped density were determined for the blend of all the formulations to assess free flow characteristics [6]. Then, the prepared compressed tablets were evaluated by different tests.

\section{The angle of repose}

The angle of repose " $\theta$ " is determined by fixed funnel and free-standing cone method using the following equation:

$\theta=\tan ^{-1}(\mathrm{~h} / \mathrm{r})$

Where $\theta=$ angle of repose, $h=$ height of the pile, and $r=$ radius of the pile.

\section{Carr's compressibility index and Hausner's Ratio}

Bulk density was measured by filling the powder in measuring cylinder and the tapped density was determined by tapping method [6]. Compressibility index and Hausner's ratio are calculated using the following equations:

Carr 's compressibility Index $=\frac{\text { Tapped density-Bulk density }}{\text { Tapped density }}$ X 100

Hausner's ratio is calculated as the simple difference between the tapped density and bulk density.

Hausner's ratio $=\frac{\text { Tapped density }}{\text { bulk density }}$

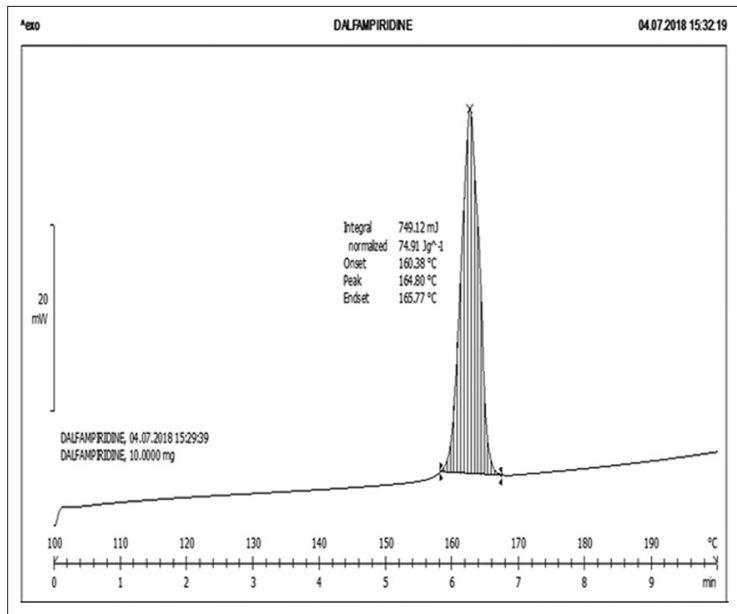

Fig. 3: Differential scanning calorimetry of dalfampridine

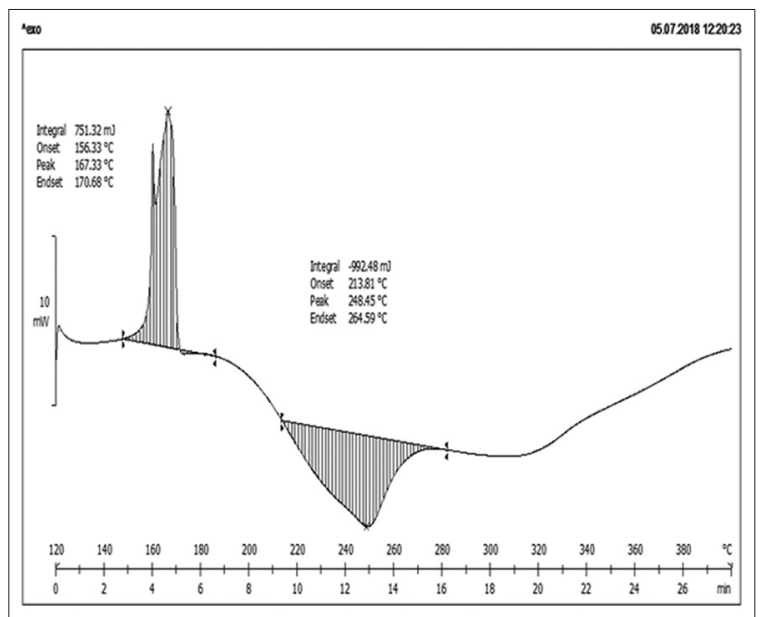

Fig. 4: Differential scanning calorimetry of Oryza sativa cellulose and dalfampridine

As all powder blends of all formulations evidenced good flow properties, tablets were compressed for all F1-F8.

\section{Evaluation of compressed tablets}

The compressed tablets were evaluated by thickness, hardness, friability, drug content uniformity, and in vitro drug release studies.

Thickness was determined by Vernier caliper. Hardness was tested using Monsanto hardness tester, and friability test was carried out using Roche Friability Apparatus (Veego Instruments Ltd., India).

\section{Drug content uniformity}

Drug content estimation was carried out by collecting ten tablets from each batch at random [8]. The tablets were powdered, and the fine powder (equivalent to $10 \mathrm{mg}$ of dalfampridine) was transferred to a $100 \mathrm{ml}$ volumetric flask and dissolved in water. The solutions were made up to the volume, filtered, and suitably diluted, and drug contents were estimated using UV-visible spectrophotometer (Systronics, India) at $262 \mathrm{~nm}$.

\section{Disintegration test}

The disintegration time of tablets was determined for 6 tablets using Thermionic Tablet Disintegration Test Apparatus [8]. pH 7.4 phosphate buffer maintained at $37 \pm 0.5^{\circ} \mathrm{C}$ in isothermal water bath was used as a medium.

In vitro drug release studies of prepared tablets

In vitro dissolution release studies were carried out for the prepared tablets of flutamide and glimepiride in comparison with the commercial 


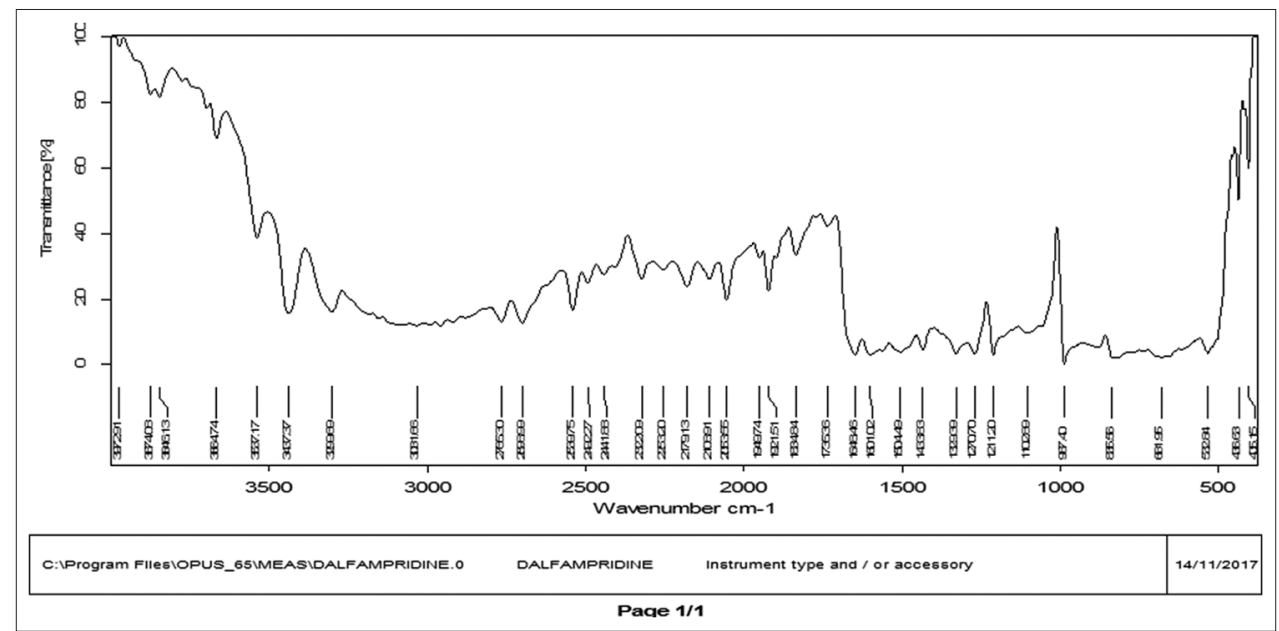

Fig.5: Fourier-transform infrared of dalfampridine

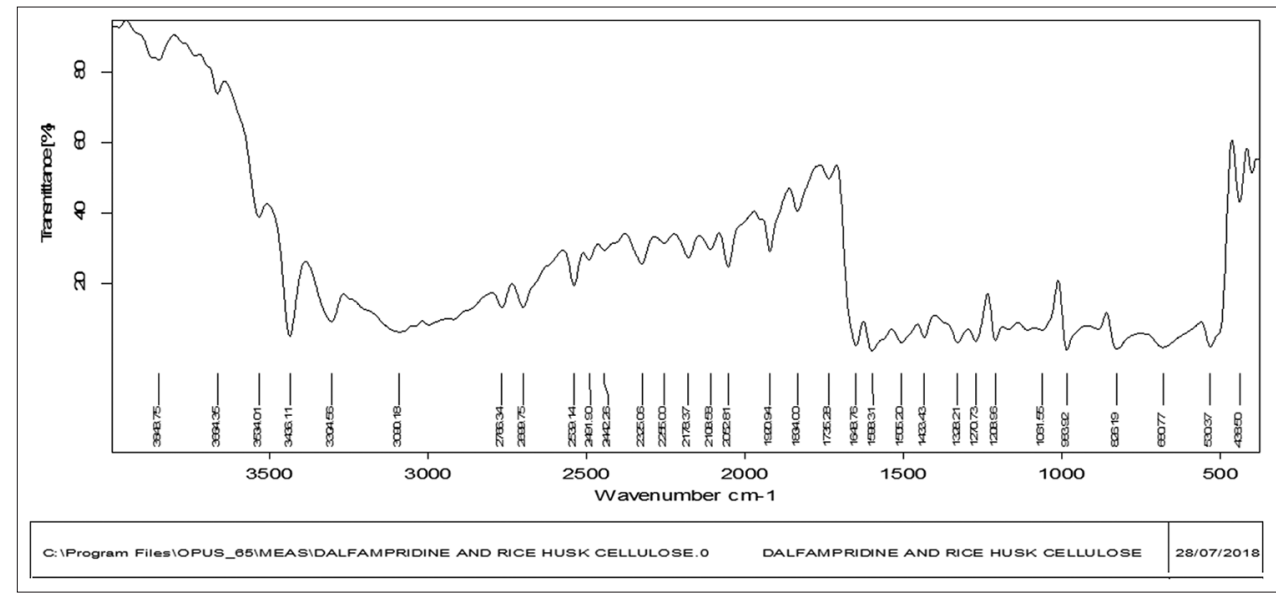

Fig. 6: The alkali (liquid ammonia)-treated Oryza sativa cellulose Fourier-transform infrared

Table 4: Pre-compression parameters of formulation, F1-F8 (n=3 \pm SD)

\begin{tabular}{llllll}
\hline $\begin{array}{l}\text { Formulation } \\
\text { code }\end{array}$ & $\begin{array}{l}\text { Bulk Density } \\
(\mathbf{g} / \mathbf{m L})\end{array}$ & $\begin{array}{l}\text { Tapped Density } \\
(\mathbf{g} / \mathbf{m L})\end{array}$ & $\begin{array}{l}\text { Compressibility } \\
\text { Index }(\mathbf{\%})\end{array}$ & $\begin{array}{l}\text { Hausner's } \\
\text { Ratio }\end{array}$ & $\begin{array}{l}\text { Angle of } \\
\text { Repose }(\boldsymbol{\theta})\end{array}$ \\
\hline F1 & $0.80 \pm 0.13$ & $0.942 \pm 0.2$ & $15.07 \pm 1.2$ & $1.14 \pm 0.01$ & $25.12 \pm 0.94$ \\
F2 & $0.78 \pm 1.0$ & $0.931 \pm 0.6$ & $16.21 \pm 0.2$ & $1.19 \pm 0.19$ & $25.86 \pm 0.35$ \\
F3 & $0.81 \pm 0.7$ & $0.932 \pm 0.1$ & $13.09 \pm 0.3$ & $1.15 \pm 0.32$ & $25.21 \pm 0.58$ \\
F4 & $0.80 \pm 0.2$ & $0.936 \pm 0.8$ & $14.52 \pm 0.4$ & $1.17 \pm 1.09$ & $25.23 \pm 0.21$ \\
F5 & $0.78 \pm 0.9$ & $0.925 \pm 0.5$ & $15.06 \pm 0.7$ & $1.18 \pm 0.07$ & $25.21 \pm 0.98$ \\
F6 & $0.80 \pm 0.2$ & $0.931 \pm 0.9$ & $14.07 \pm 0.2$ & $1.16 \pm 0.03$ & $26.45 \pm 0.43$ \\
F7 & $0.82 \pm 0.3$ & $0.928 \pm 0.1$ & $11.63 \pm 0.6$ & $1.13 \pm 0.05$ & $26.23 \pm 0.74$ \\
F8 & $0.80 \pm 1.4$ & $0.927 \pm 0.3$ & $13.70 \pm 0.3$ & $1.15 \pm 0.08$ & $25.88 \pm 0.97$ \\
\hline
\end{tabular}

Table 5: Evaluation parameters of formulation, F1-F8 (n=3 \pm SD)

\begin{tabular}{lllll}
\hline $\begin{array}{l}\text { Formulation } \\
\text { Code }\end{array}$ & $\begin{array}{l}\left.\text { Hardness in } \mathbf{( K g} / \mathbf{C m}^{2}\right) \\
(\mathbf{n = 3})\end{array}$ & $\begin{array}{l}\text { Friability } \\
\mathbf{( n = 6 )}\end{array}$ & $\begin{array}{l}\text { Thickness }(\mathbf{m m}) \\
\mathbf{( n = 3 )}\end{array}$ & $\begin{array}{l}\text { Disintegration time }(\mathbf{m i n}) \\
\mathbf{( n = 6 )}\end{array}$ \\
\hline F1 & $7.94 \pm 0.12$ & $0.405 \pm 0.40$ & $4.231 \pm 0.01$ & $7 \pm 0.3$ \\
F2 & $7.84 \pm 0.86$ & $0.405 \pm 0.40$ & $4.233 \pm 0.01$ & $6.56 \pm 0.2$ \\
F3 & $8.01 \pm 0.14$ & $0.420 \pm 0.07$ & $4.248 \pm 0.02$ & $6.48 \pm 0.2$ \\
F4 & $6.10 \pm 0.11$ & $0.012 \pm 0.10$ & $4.244 \pm 0.01$ & $7.52 \pm 0.3$ \\
F5 & $7.41 \pm 0.14$ & $0.015 \pm 0.01$ & $4.256 \pm 0.02$ & $7.45 \pm 0.3$ \\
F6 & $8.14 \pm 0.29$ & $0.007 \pm 0.06$ & $4.246 \pm 0.01$ & $7.80 \pm 0.1$ \\
F7 & $4.25 \pm 0.10$ & $0.422 \pm 0.52$ & $4.234 \pm 0.01$ & $8.50 \pm 0.1$ \\
F8 & $5.10 \pm 0.05$ & $0.006 \pm 0.04$ & $4.248 \pm 0.01$ & $8.41 \pm 0.3$ \\
\hline
\end{tabular}

tablets of both the drugs [9]. The test was carried out using USP XXI Dissolution Testing Apparatus Type II, (Electrolab, India) using $900 \mathrm{ml}$ of $\mathrm{pH} 6.8$ phosphate buffer maintained at $37 \pm 0.5^{\circ} \mathrm{C}$ as medium. Stirring speed was maintained at $50 \mathrm{rpm}$. Aliquot samples were withdrawn at 
pre-determined time intervals and filtered through $0.45 \mu \mathrm{m}$ Millipore filter, suitably diluted wherever necessary, and were analyzed for the drug content by UV-visible spectrophotometer (Systronics, India). The volume withdrawn at each time interval was replaced with fresh dissolution medium maintained at the same temperature. Each study was performed in triplicate and mean values are reported.

\section{Assessment of release kinetics of dalfampridine tablets}

Rate and mechanism of drug release from matrix tablets were assessed by fitting the data into zero order kinetics $\left(\mathrm{Q}=\mathrm{K}_{\mathrm{o}} \mathrm{t}\right)$, first-order kinetics $\left(\log Q=\log Q_{0}+K_{1} t / 2.303\right)$, Higuchi's model $(Q=K H t 1 / 2)$, and KorsmeyerPeppas model [10] $\left(\mathrm{F}=(\mathrm{Mt} / \mathrm{M})=\mathrm{K} \mathrm{t}_{\mathrm{n}}\right)$.

\section{RESULTS AND DISCUSSION}

\section{Characterization of cellulose}

Solubility

Prepared cellulose from OSO was completely soluble in a selected solvent system $\left(\mathrm{NaOH} / \mathrm{H}_{2} \mathrm{O}\right)$ pre-cooled to $-1^{\circ} \mathrm{C}$. This supported the solubility characteristics of celluloses reported in literature [7].

\section{FTIR}

FTIR spectrum of OS cellulose is shown in Fig. 1. The absorption peaks are shown in Table 2. As revealed, $\mathrm{OH}$ - stretching is at $3386, \mathrm{C}=0$ stretching was observed at 1896, CH-bending was observed at 1315.84, C-O stretching was observed at 1236.89, C-O-C Pyranose ring was observed at 1388.47 , and $\beta$-glycoside linkage was observed at 888.36 . All these values are coinciding with the values of those groups reported for cellulose in the literature [11,3].

\section{Melting point}

Melting point observed for the cellulose of $\mathrm{OS}$ is $456^{\circ} \mathrm{C}$ the value which is closer to value reported in literature $\left(467^{\circ} \mathrm{C}\right)[12]$.

\section{DSC of OS cellulose}

DSC thermogram of cellulose of OS is presented in Fig. 2. It is observed that the melting point is present at $316.83^{\circ} \mathrm{C}$. This value is coinciding with the reported range of melting point $\left(315-400^{\circ} \mathrm{C}\right)$ for cellulose materials. Hence, it is concluded that the extraction procedure utilized in the present work is suitable to produce cellulose with optimum characteristics to be used in drug development.

Drug-excipient interaction study of dalfampridine with cellulose of OS DSC thermogram of dalfampridine as presented in Fig. 3 showed a melting peak at $164.80^{\circ} \mathrm{C}$, whereas its mixture with dalfampridine with cellulose showed melting peak at $167^{\circ} \mathrm{C}$ (Fig. 4). This slight modification is ignored and cosidered as incopamatibility.

The FTIR spectrum of dalfampridine and its mixture with cellulose and drug is shown in Fig. 5 and Fig. 6, respectively. Absorption peaks of both are shown in Table 3 for easy comparison. Dalfampridine peaks, NH-stretch at 3437.37, CH-stretch (aromatic) at 3031.66, $\mathrm{C}=\mathrm{N}$ bond at 1648.46, $\mathrm{C}=\mathrm{C}$ bond 1504.49, and $\mathrm{CH}$-bending at 1433.83 are not modified appreciably in Fig. 6. Hence, it is considered that there is no incompatibility dalfampridine and OS cellulose mixture [13].

After assessing compatibility between dalfampridine and cellulose of OS, directly compressed tablets of dalfampridinewere prepared (8nos.F1 to F8).

Before compression, pre-compression parameters of blends were assessed and are shown in Table 4. Compressibility index and Hausner's ratio were in the range of $11.63 \%-16.21 \%$ and $1.13-1.19$, respectively. The angle of repose between $25.12 \pm 0.94$ and $26.45 \pm 0.43$ indicted good flow properties of all prepared formulations, F1-F8.

Hence, all formulations were compressed directly and evaluated. Results of various parameters of F1 to F8 are given in Table 5. Postcompression parameters of prepared directly compressed tablet

Table 6: Dissolution profiles of formulations, F1-F8

\begin{tabular}{|c|c|c|c|c|c|c|c|c|}
\hline \multirow[t]{2}{*}{ Time (h) } & \multicolumn{8}{|c|}{$\%$ Cumulative Drug Release ( $n=3 \pm S D$ ) } \\
\hline & F1 & F2 & F3 & $\mathbf{F 4}$ & F5 & F6 & F7 & F8 \\
\hline $30 \mathrm{~min}$ & $19 \pm 0.1$ & $10 \pm 0.3$ & $12 \pm 0.1$ & $18 \pm 0.3$ & $23 \pm 0.2$ & $15 \pm 0.3$ & $17 \pm 0.1$ & $24 \pm 0.2$ \\
\hline $45 \mathrm{~min}$ & $23 \pm 0.2$ & $22 \pm 0.2$ & $29 \pm 0.1$ & $26 \pm 0.2$ & $26 \pm 0.1$ & $21 \pm 0.3$ & $22 \pm 0.1$ & $29 \pm 0.1$ \\
\hline 1 & $34 \pm 0.1$ & $38 \pm 0.2$ & $43 \pm 0.1$ & $36 \pm 1.2$ & $38 \pm 0.1$ & $29 \pm 0.7$ & $36 \pm 0.1$ & $32 \pm 0.1$ \\
\hline 2 & $38 \pm 1.2$ & $38 \pm 0.5$ & $55 \pm 0.4$ & $40 \pm 1.4$ & $40 \pm 0.3$ & $29 \pm 1.2$ & $36 \pm 0.2$ & $38 \pm 0.7$ \\
\hline 3 & $38 \pm 0.3$ & $44 \pm 0.8$ & $60 \pm 0.8$ & $43 \pm 0.8$ & $46 \pm 0.4$ & $35 \pm 0.2$ & $38 \pm 0.3$ & $40 \pm 1.2$ \\
\hline 4 & $40 \pm 0.3$ & $45 \pm 0.7$ & $61 \pm 0.6$ & $46 \pm 0.9$ & $46 \pm 0.8$ & $56 \pm 0.3$ & $38 \pm 0.1$ & $45 \pm 0.8$ \\
\hline 5 & $46 \pm 0.7$ & $45 \pm 0.1$ & $63 \pm 0.7$ & $48 \pm 0.6$ & $46 \pm 0.7$ & $63 \pm 0.2$ & $40 \pm 0.3$ & $56 \pm 2.1$ \\
\hline 6 & $55 \pm 0.6$ & $48 \pm 0.1$ & $64 \pm 1.2$ & $48 \pm 0.1$ & $46 \pm 0.1$ & $69 \pm 0.5$ & $46 \pm 0.8$ & $64 \pm 0.8$ \\
\hline 7 & $68 \pm 1.2$ & $48 \pm 0.4$ & $66 \pm 1.4$ & $55 \pm 0.2$ & $54 \pm 0.1$ & $70 \pm 0.7$ & $50 \pm 0.7$ & $66 \pm 0.6$ \\
\hline 8 & $76 \pm 0.9$ & $51 \pm 0.3$ & $70 \pm 0.6$ & $66 \pm 0.3$ & $65 \pm 0.2$ & $74 \pm 0.3$ & $55 \pm 0.6$ & $70 \pm 0.4$ \\
\hline 9 & $88 \pm 1.2$ & $66 \pm 0.3$ & $74 \pm 0.8$ & $77 \pm 0.3$ & $78 \pm 0.3$ & $74 \pm 0.3$ & $68 \pm 1.2$ & $72 \pm 0.2$ \\
\hline 10 & $90 \pm 1.4$ & $82 \pm 0.7$ & $86 \pm 1.2$ & $79 \pm 0.6$ & $80 \pm 0.7$ & $74 \pm 0.4$ & $78 \pm 1.4$ & $84 \pm 0.1$ \\
\hline 11 & $95 \pm 1.3$ & $89 \pm 0.8$ & $88 \pm 1.3$ & $85 \pm 0.8$ & $85 \pm 0.3$ & $87 \pm 0.4$ & $78 \pm 1.2$ & $88 \pm 0.1$ \\
\hline 12 & $95 \pm 0.1$ & $94 \pm 0.2$ & $90 \pm 0.1$ & $94 \pm 0.1$ & $94 \pm 0.2$ & $96 \pm 0.5$ & $83 \pm 0.8$ & $95 \pm 0.2$ \\
\hline
\end{tabular}

Table 7: Model independent and dependent parameters of dissolution data

\begin{tabular}{|c|c|c|c|c|c|}
\hline \multirow[t]{2}{*}{ Formulation code } & \multirow[t]{2}{*}{ Zero-order $\mathbf{R}^{2}$ value } & \multirow[t]{2}{*}{ First-order $\mathbf{R}^{2}$ value } & \multirow[t]{2}{*}{ Higuchi $R^{2}$ value } & \multicolumn{2}{|c|}{ Korsmeyer } \\
\hline & & & & $\mathbf{R}^{2}$ & $\mathbf{N}$ \\
\hline F1 & 0.964 & 0.905 & 0.932 & 0.739 & 1.36 \\
\hline F2 & 0.862 & 0.771 & 0.830 & 0.463 & 1.31 \\
\hline F3 & 0.812 & 0.918 & 0.880 & 0.417 & 1.43 \\
\hline F4 & 0.943 & 0.811 & 0.909 & 0.657 & 1.38 \\
\hline F5 & 0.935 & 0.804 & 0.879 & 0.694 & 1.43 \\
\hline F6 & 0.925 & 0.824 & 0.960 & 0.752 & 1.28 \\
\hline F7 & 0.918 & 0.876 & 0.872 & 0.614 & 1.36 \\
\hline F8 & 0.989 & 0.886 & 0.970 & 0.848 & 1.40 \\
\hline
\end{tabular}




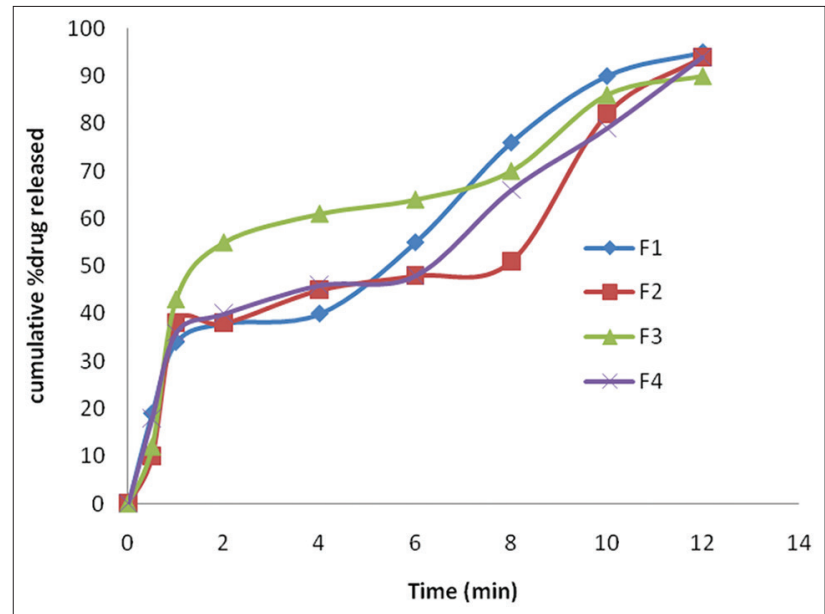

Fig. 7: Percentage drug release profiles of formulations, F1-F4

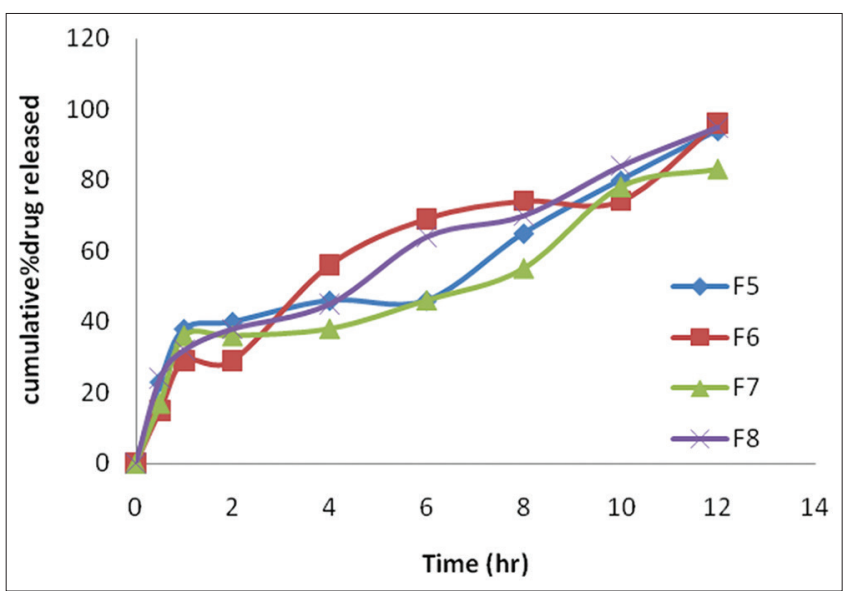

Fig. 8: Percentage drug release profiles of formulations, F5-F8

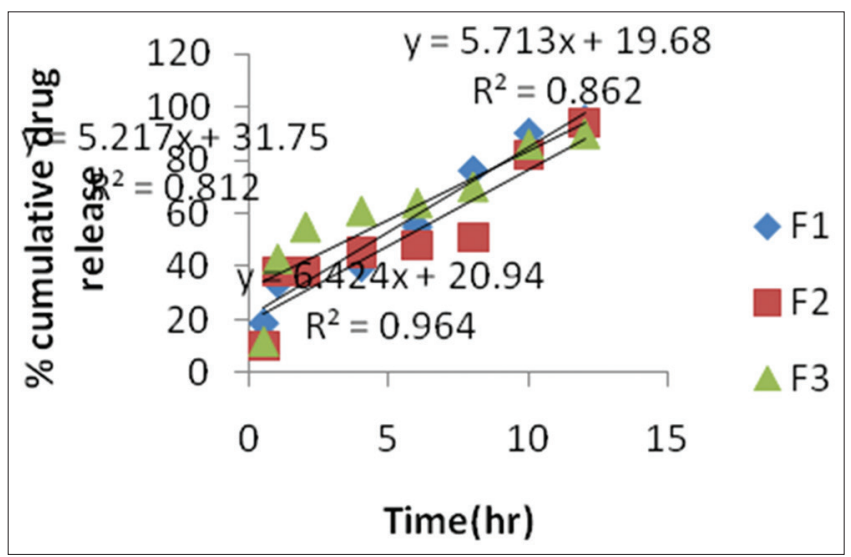

Fig. 9: Zero order for F1-F3

formulations, F1-F8, of dalfampridine are given in Table 14. Weight variation values are in the range of $0.03-0.09 \%$. Hardness is in between 5.10 and $8.14 \mathrm{~kg} / \mathrm{cm}^{2}$. Thicknesses are from $4.231 \mathrm{~mm}$ to $4.256 \mathrm{~mm}$. Friability is in the acceptable values of $0.007-0.422 \%$. Disintegration time obtained is in a reasonable range of $6.48-8.50 \mathrm{~min}$, and drug content is in $87-97 \%$. Hence, these results indicated that all the parameters of prepared formulations, F1-F8, are in official limits.

In vitro drug release studies of prepared tablets

In vitro drug release data as shown in Table 6 and Figs. 7 and 8 clearly indicate prolonged and controlled drug delivery of dalfampridine for $12 \mathrm{~h}$.

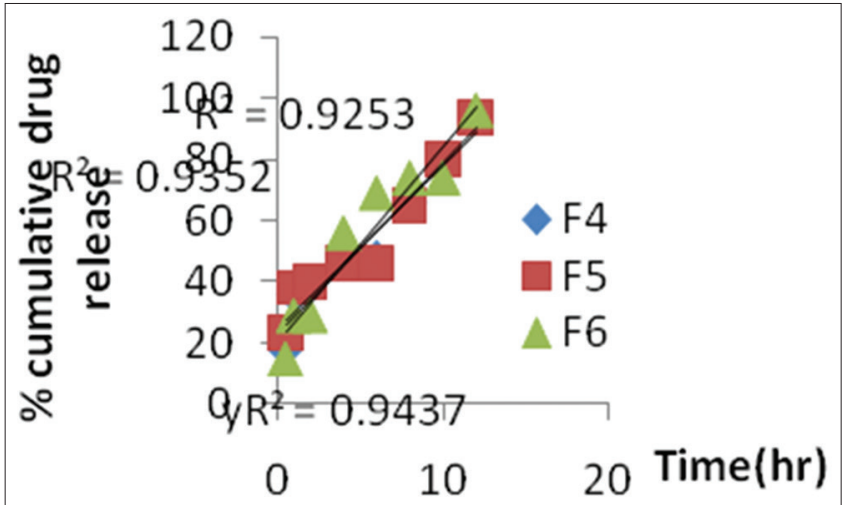

Fig. 10: Zero order for F4-F6

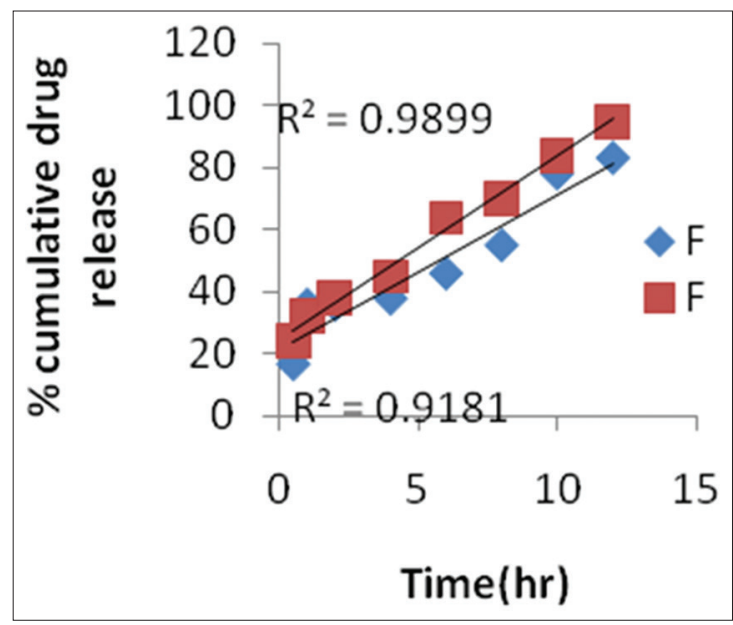

Fig. 11: Zero order for F7-F8

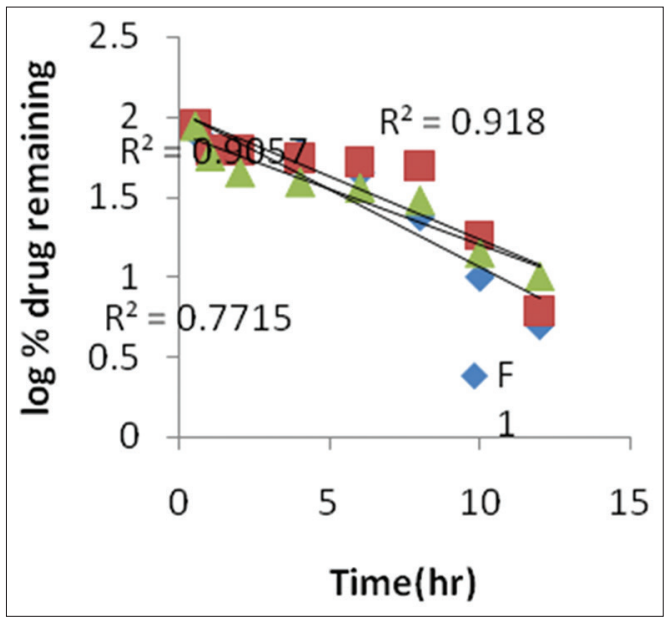

Fig. 12: First order for F1-F3

However, there is a ideal controlled release from F6 without exhibiting burst release ( $\geq 31 \%$ ) [14] within $1 \mathrm{~h}$. Hence, from these studies, F6 is considered as best formulation assessed for release kinetics.

\section{Assessment of release kinetics of dalfampridine tablets}

Zero order, first order, Higuchi, and Korsmeyer plots are shown in Figs. 9-20 and the corresponding " $r$ " values are in given in Table 7. " $r$ " values closer unity in case of zero-order and Higuchi plots indicate that the release kinetics of dalfampridine from prepared tablets is followed in zero-order and by mechanism of diffusion. 


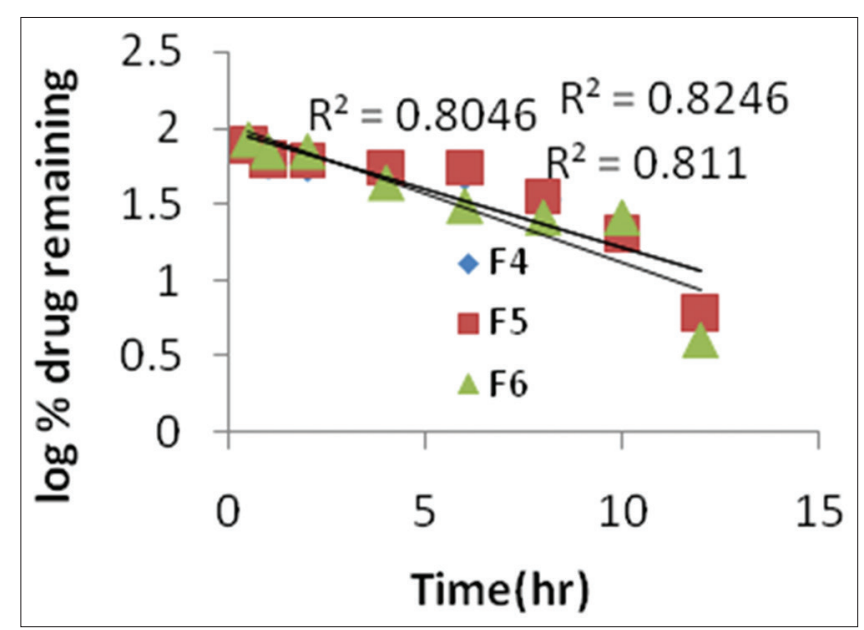

Fig. 13: First order for F4-F6

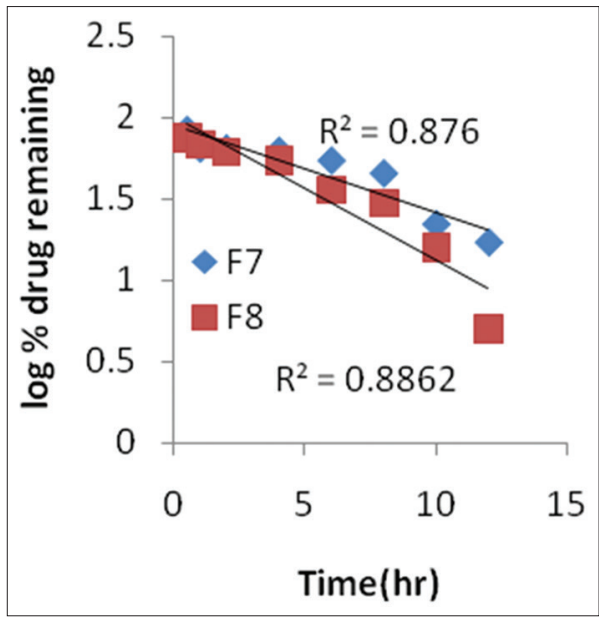

Fig. 14: First order for F7 and F8

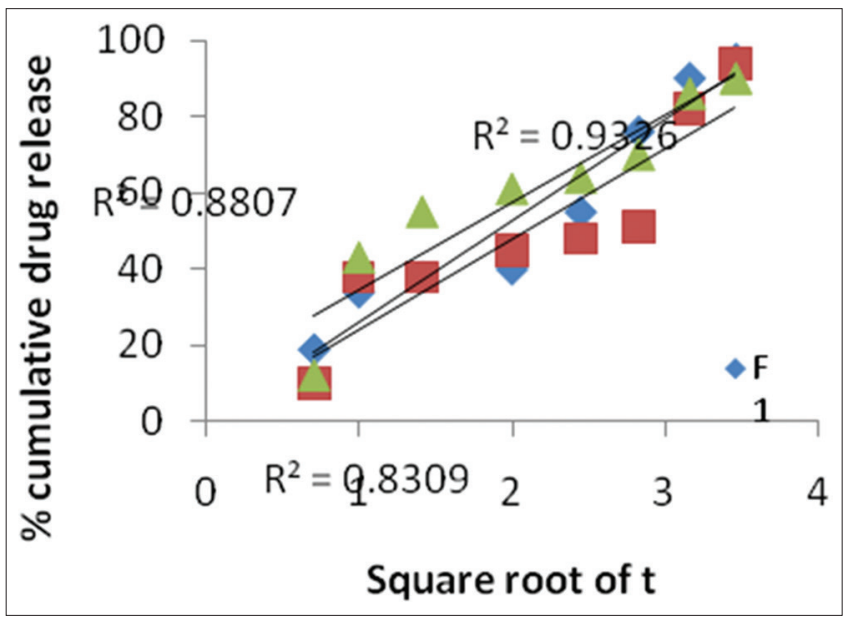

Fig. 15: Higuchi model for F1-F3

\section{CONCLUSION}

"Hence from these studies, it is concluded that cellulose of OS can be used successfully for the production of directly compressed tablets of dalfampridine to elicit optimum characteristics including controlled drug delivery for $12 \mathrm{h."}$

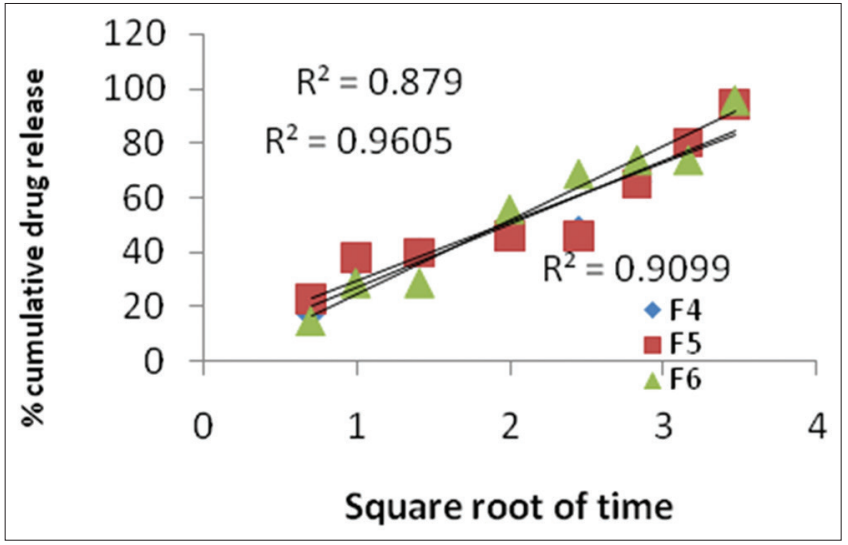

Fig. 16: Higuchi model for F4-F6

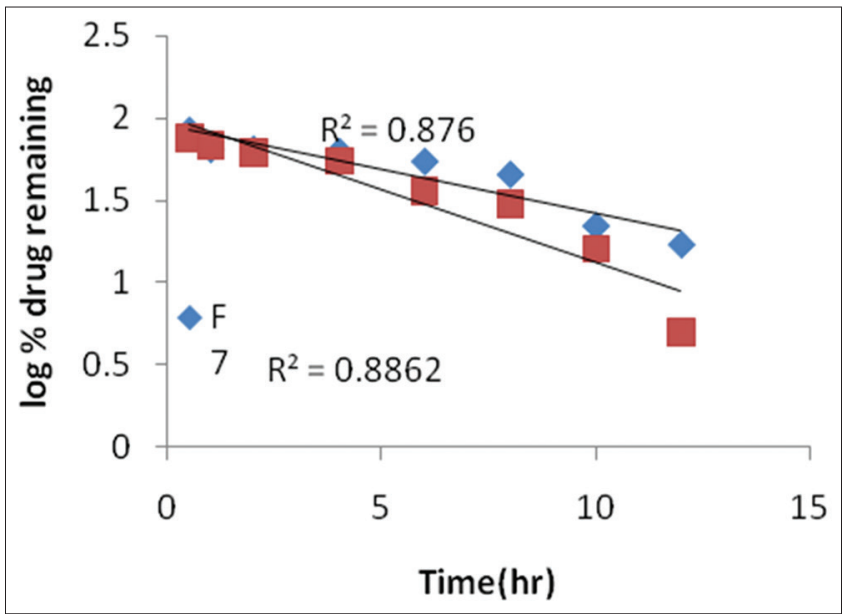

Fig. 17: Higuchi model for F7- F8

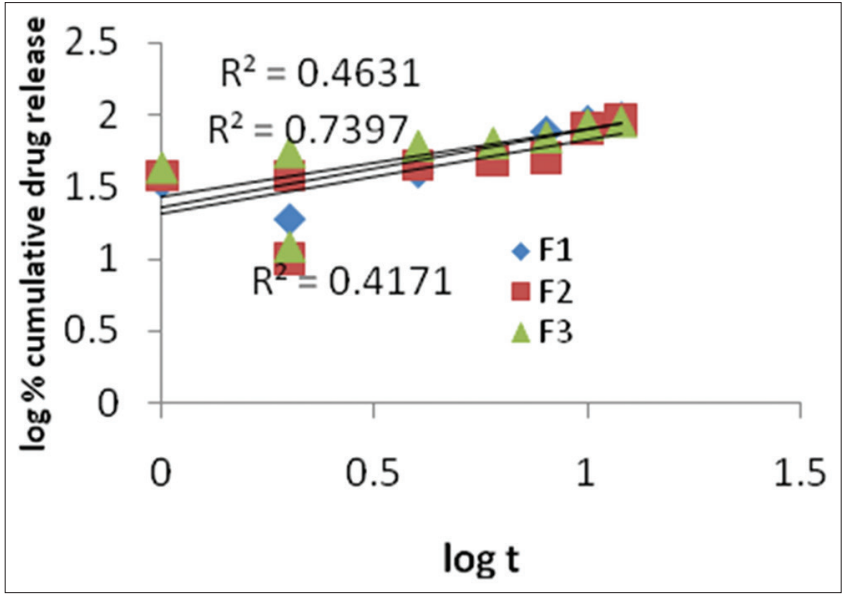

Fig. 18: Korsmeyer model for F1-F3

\section{ACKNOWLEDGMENTS}

The authors acknowledge their gratitude to DST-CURIE facilities of SRI PADMAVATI MAHILA VISVAVIDYALAYAM, Tirupati, for providing FTIR, DCS, SEM, and dissolution testing apparatus as and when required for the study.

\section{AUTHORS' CONTRIBUTIONS}

Jeevanajyothi B has designed the plan of present work and responsible for this novel work and preparation of the manuscript. Mounika has done the experiments involved in the research. 


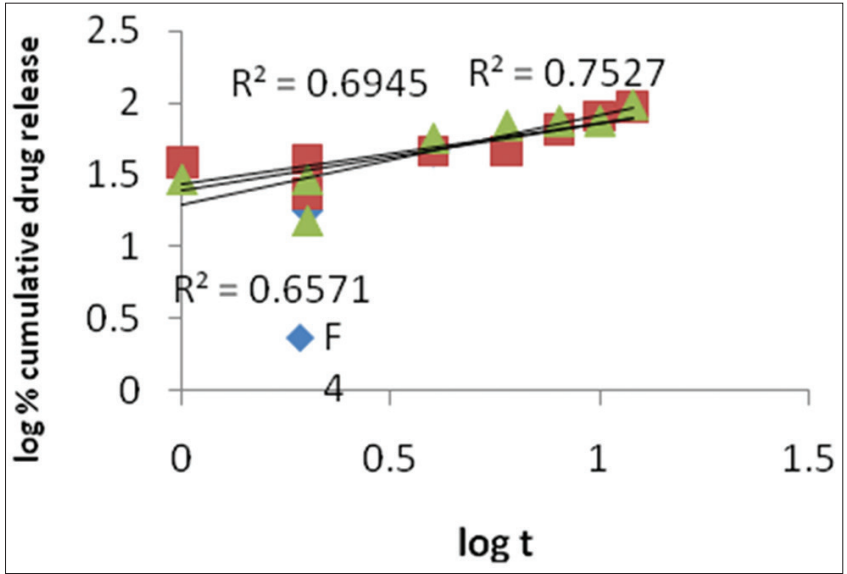

Fig. 19: Korsmeyer model for F4-F6

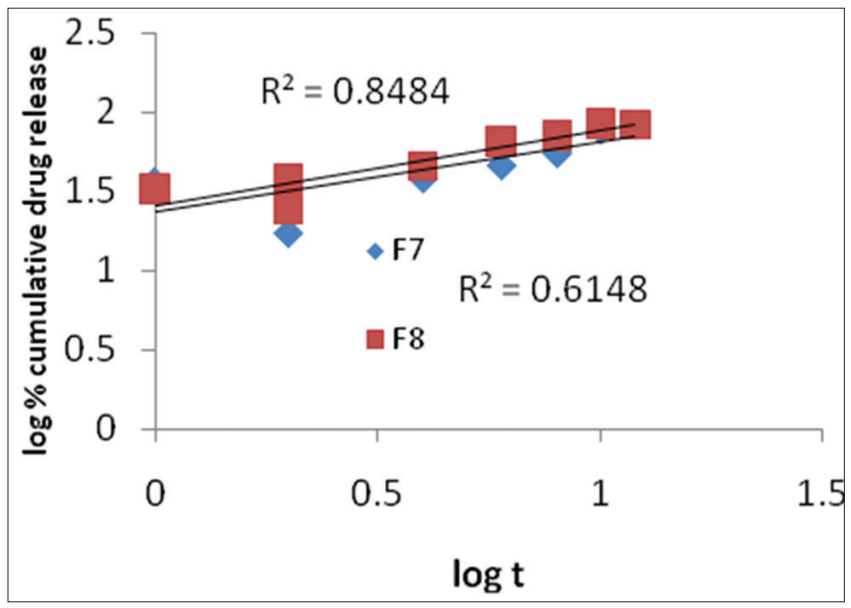

Fig. 20: Korsmeyer model for F7-F8

\section{CONFLICTS OF INTEREST}

The authors have no conflicts of interest.

\section{REFERENCES}

1. Sahraian MA, Maghzi AH, Etemadifar M, Minagar A. Dalfampridine: Review of its efficacy in improving gait in patients with multiple sclerosis. J Cent Nerv Syst Dis 2011;3:87-93.

2. Jorfi EM, Foster J. Recent advances in nanocellulose for biomedical applications. J Appl Biopolym Sci 2014;24:1-19.

3. Das AM, Ali AA, Hazarika MP. Synthesis and characterization of cellulose acetate from Oryza sativa: Eco-friendly condition. Carbohydr Polym 2014;112:342-9.

4. Ahmad Z, Rozyanty AR, Nawawi WI. Isolation and characterization of microcrystalline cellulose (MCC) from Oryza sativa (RH). EDP Sci 2016;2:22-45

5. Moran JI, Alvarez VA, Cyras VP, Vazquez A. Extraction of cellulose and preparation of nanocellulose from sisal fibers. Cellulose 2008;15:149-59.

6. Kihlman M, Medronho BF, Romano AL, Germgard U, Lindman B. Cellulose dissolution in an alkali-basedsolvent: Influence of additives and pretreatments. J Braz Chem Soc 2013;24:295-303.

7. Venugopal V. Formulation and optimization of sustained release tablets of tramadol and dalfampridine by factorial design model. Asian Med Sci Technol 2015;2:1-243.

8. Haritha B. A review on the evaluation of tablets. J Formul Sci Bioavailab 2017;1:1-5.

9. Naveen Goyal, Anil Kumar. Formulation and in vitro evaluation of salbutamol sulphate and theophylline extended-release tablets using modified polymers. Int J Pharm Pharm Sci 2018;10:67-71.

10. Srikanthreddy P, Bose PS, Saritha D, Sruthi V. Formulation and evaluation of colon targeted matrix tablet usinf natural tree gums. Int J Pharm Pharm Sci 2018;10:92-7.

11. Rosa SM, Rehman N, De Miranda MI, Nachtigall SM, Bica CI. Chlorine-free extraction of cellulose from Oryza sativa and whisker isolation. Carbohydr Polym 2012;87:1131-8.

12. Krumm C, Pfaendtner J, Dauenhauer PJ. Millisecond pulsed films unify the mechanisms of cellulose fragmentation. Chem Mater 2016;28:2-12.

13. Reddy CS, Reddy YR, Devanna N. formulation and optimization of the extended-release tablets of dalfampridine by 23 factorial design. J Pharm Sci Innov 2016;5:27-37.

14. Ceballos A, Cirri M, Maestrelli F, Corti G, Mura P. Influence of formulation and process variables on in vitro release of theophylline from directly-compressed Eudragit matrix tablets. II Farmaco 2005;60:913-8 